\title{
INTERNAL FIXATION AFTER INTRA-ARTICULAR FRACTURE OF THE DISTAL ULNA
}

\author{
M. C. Solan, R. Rees, S. Molloy, M. T. Proctor \\ From Kingston Hospital, Kingston-upon-Thames, England
}

W e describe a patient who sustained a displaced isolated intra-articular fracture of the distal ulna, causing limitation of rotation of the forearm. The extent of displacement of the fracture which was not evident on plain radiographs was revealed by $\mathrm{CT}$. The fracture was reduced and internally fixed using a standard technique applicable to the fixation of fractures of the radial head. Full movement was restored. An isolated injury to the distal ulna is rare and requires careful clinical and radiological assessment.

J Bone Joint Surg [Br] 2003;85-B:279-80.

Received 9 October 2001; Accepted after revision 18 April 2002

Normal rotation of the forearm combines with shoulder and elbow function to enable the hand to be positioned accurately. The radioulnar joints allow the mobile radius to rotate around the fixed ulna. ${ }^{1}$ Injury to these joints may result in a reduced range of rotation of the forearm. We describe a patient with an isolated fracture of the distal ulna in which there was marked loss of rotation.

\section{Case report}

A 48-year-old man was assaulted and raised his left arm in order to protect himself. Clinical examination revealed local tenderness and swelling over the ulnar aspect of the distal forearm. There was full active pronation with, however, complete loss of supination. Infiltration of the site of the fracture with local anaesthetic did not abolish this block to rotation.

Plain radiographs showed a fracture of the head of the ulna (Fig. 1). The loss of rotation after an injection of local anaesthetic suggested a mechanical block. CT showed a large fracture involving the distal radio-ulnar joint (Fig. 2). Surgery was carried out through a standard dorsal approach protecting the dorsal ulnar sensory nerve. A single, large, osteochondral fragment was found. No other injury was identified and the triangular fibrocartilage complex was intact. The fracture was reduced and fixed with a cannulated compression screw. The technique was similar to that used by the senior author (MTP) for the fixation of fractures of the head of the radius. Postoperatively, the patient was immobilised in an above-elbow cast for two weeks. Rotation was then allowed and a below-elbow cast retained for a further four weeks. The fracture

M. C. Solan, FRCS Orth, Specialist Registrar

R. Rees, MRCS, Senior House Officer

S. Molloy, MRCS, Specialist Registrar

M. T. Proctor, FRCS Orth, Consultant Orthopaedic Surgeon

Kingston Hospital, Galsworthy Road, Kingston-upon-Thames KT2 7QB, UK.

Correspondence should be sent to Mr M. C. Solan at 7 Monks Walk, Reigate, Surrey RH2 OSS, UK.

(C)2003 British Editorial Society of Bone and Joint Surgery doi.10.1302/0301-620X.85B2.13459 \$2.00

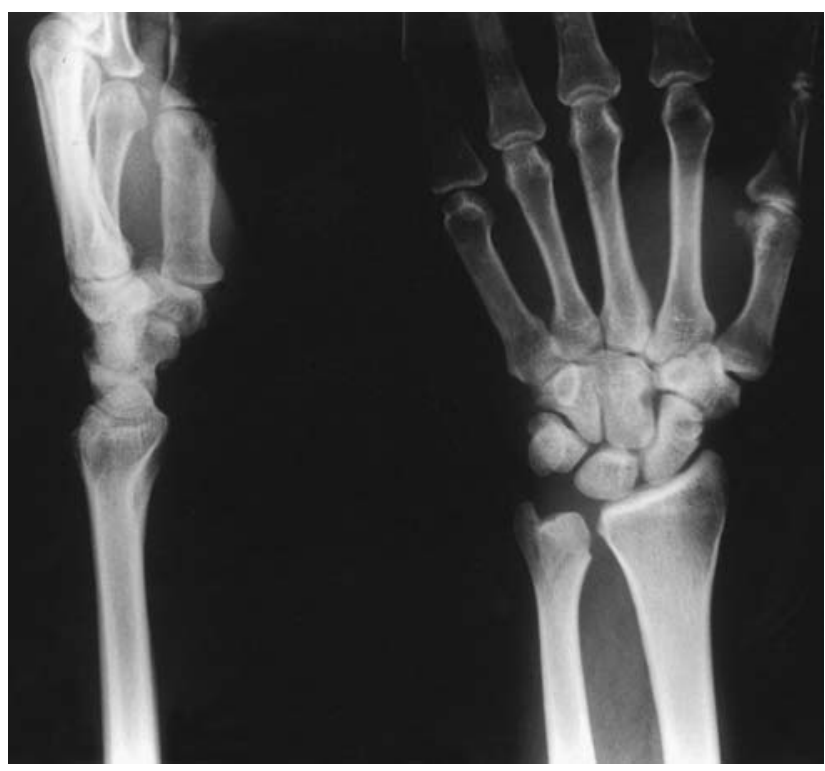

Fig. 1

Lateral and anteroposterior radiographs of the distal radius and ulna after injury.

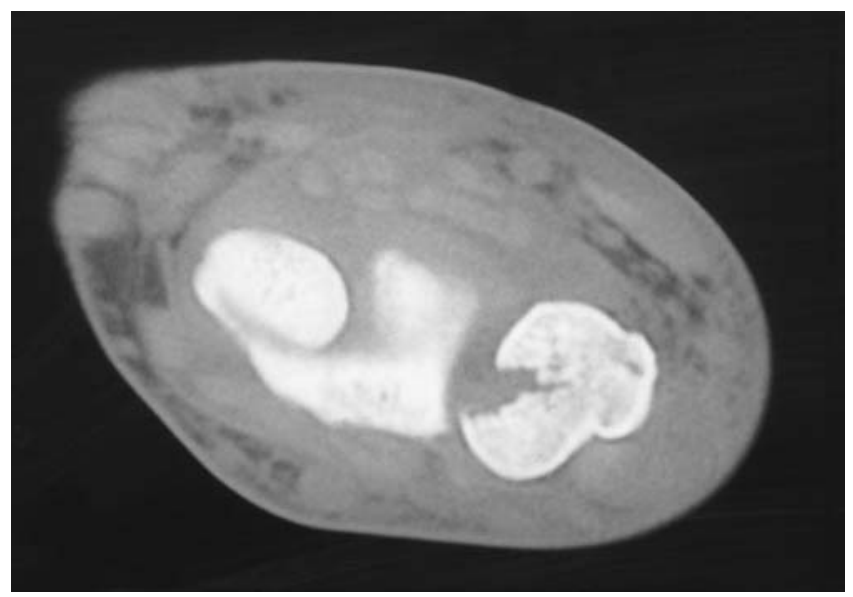

Fig. 2

Axial CT of the distal radio-ulnar joint.

united uneventfully. A full range of rotation, identical to the uninjured side, was restored.

\section{Discussion}

The distal radio-ulnar joint is a complex anatomical structure. Its stability is important, both for function of the wrist and for rotation 
of the radius about the ulna. ${ }^{2}$ Injury to the distal ulna often accompanies a fracture of the distal radius and may be associated with dislocation of the distal radio-ulnar joint. ${ }^{3}$ More commonly recognised are distal radio-ulnar disruptions associated either with a fracture of the distal radius (Galeazzi) or of the radial head (EssexLopresti).

Isolated fractures of the head of the ulna are rare. Only one case has been reported in the literature. ${ }^{4}$ In order to allow normal rotation of the forearm, both proximal and distal radioulnar joints must be normal. At presentation, our patient could not supinate the forearm beyond neutral. To exclude pain as the cause for this block, local anaesthetic was injected into the site of the fracture and the patient re-examined. Although this examination was not uncomfortable the block to rotation persisted. We therefore concluded that it had a mechanical cause, and was caused by displacement of the fracture. This was confirmed by CT.

When managing rare injuries basic principles should not be forgotten. Abnormal physical findings should be investigated, and, if proper assessment is impossible, examination under local or gen- eral anaesthesia may be useful. For intra-articular injuries, CT is the imaging technique of choice.

Displaced intra-articular fractures should be reduced and stabilised. By using the same principles of treatment which have become established for the management of displaced fractures of the radial head we were able to restore normal function to our patient.

No benefits in any form have been received or will be received from a commercial party related directly or indirectly to the subject of this article.

\section{References}

1. Sinnatamby CS. Last's anatomy. Tenth edition. Edinburgh, etc: Churchill Livingstone; 1998.

2. Faierman E, Jupiter JB. The management of acute fractures involving the distal radioulnar joint and distal ulna. Hand Clin 1998;14:213-29.

3. Tamura Y, Inoue G. Dislocation of the distal radioulnar joint associated with an intra-articular fracture of the ulnar head: report of two cases. $J$ Orthop Trauma 1998;12:68-70.

4. Jakab E, Ganos DL, Gagnon S. Isolated intra-articular fracture of the ulnar head. J Orthop Trauma 1993;7:290-2. 